\title{
RECENT TREND OF CHANGE OF FERTILITY IN NEPAL
}

\author{
Hikmat Bahadur Raya \\ Department of Population Studies, Terhathum M. Campus, Terhathum \\ rayahikmat88@gmail.com
}

\begin{abstract}
Fertility is one of the most predominant demographic factors of population dynamics. This article tries to analyze the trend of fertility of Nepal comparing with Global trend and the trends of other SAARC countries. This paper follows the quantitative analysis. The entire scope of discussion in this study is based on secondary sources of data. The results show that both ASFR and TFR have been continuously decreasing since 1990s. The decreasing rate is seen more in between 1998-2005s. Now the TFR is 2.3, so Nepal is in nearer to the replacement level of fertility rate. The marriage in early age is not still reduced remarkably that's why the fertility rate of this age group is not decreased as comparison to other age groups in Nepal. In the beginning, the TFRs of all SAARC countries were more than that of world. But in between past sixty decades, the TFR of this region is remarkably reduced and now it is similar to the world's figure except the Pakistan's. The TFR of Pakistan is still high in comparison to its neighbors. Fertility decline in Nepal has been occurring for several decades to till now. The reduction of fertility is beneficial in many domains, as it opens up completely for new employment and educational prospects for young women. It also creates new manpower for job market which helps to boost the economic growth. But continuous declination of fertility rate below the replacement level is not a good scenario in demography because it causes the negative growth rate of population and increase the dependency ratio.
\end{abstract}

Keywords: trend, fertility, TFR, ASFR, decline

\section{Introduction}

The level of fertility is the most important demographic factor in determining the process of population reproduction and the trend of population development, in particular the current and future population size and age structure. Fertility measures the rate at which population adds to itself by births. This measurement may be related to something e.g., totals 
population of the women on the country/region. Human fertility is responsible for biological replacement and for the maintenance of the human society. Any society replenishes itself through the process of human fertility (Bhende, A. \& Kanitkar, 1992).

The population growth is a dynamical process depends upon the growth rate. The growth rate itself depends upon the fertility, mortality rates and net migration (Adhikari \& Raya, 2018). The population growth rate of Nepal till the 1930 was negative and in 1941 1942 it was 1.16 and then with many fluctuations during the past periods now in 2011 it is 1.35 (CBS, 2014). As being one of the most important components of change of population, the study of the trend and its components is significant. Collumbien, Timaeus \& Acharya (1997) studied about the fertility trends of Nepal. This research investigated the fertility in Nepal using the measures of parity progression proposed by Brass and Juarez (1983) to detect the onset of fertility decline. The analysis was based largely on the Nepal Fertility, Family Planning and Health Survey 1991. Retherford \& Thapa (2004) studied about the trend and components of change in fertility in Nepal. Sharma (2015) tried to identify the Determinants of fertility among women of reproductive Age in Nepal. This study revels that the decline in fertility is most pronounced in the five years between 2001 and 2006 (one-child decline). Fertility has declined in every age group over the past 15 years, with largest decline seen among women 25-34 years. But over the past 5 years the largest decline is observed among women 20-24 years. This study also discussed many factors that may have contributed to this quick decline fertility in Nepal, including improved communication and greater access to modern methods of contraception. Extended spousal separations due to migrants seeking work in foreign countries, especially the Gulf countries and other Southeast Asian countries, may be another reason for the fertility decline. Shakya \& Gubhaju (2016) studied about factors contributing to fertility decline in Nepal. The study examines fertility levels, trends and differentials. It also employs a decomposition analysis technique to determine the components of changes in total fertility rate (TFR) due to marital structure and marital fertility, covering the intersurvey periods, 1991-1996, 1996-2001, 2001-2006 and 2006-2011. Increase in contraceptive use has been the primary reason for fertility decline. Age at marriage has begun to rise slowly. However, most recently, contraceptive use has not increased to 
explain the continuous fall in fertility. Factors such as an increase in male migration and induced abortion have been suggested as causes of the continued decline in fertility. Kafle (2016) examines declining fertility in a low development setting. Specifically, analyzes transitions in age at first birth and of the length of birth intervals, the variations of the length of birth intervals by selected socioeconomic and demographic factors, and the determinants of the risk of higher order birth in Nepal by using the NDHS data.

Recently the final report of NDHS 2016 has published. It gives new data of various demographic and health variables. So, this article tries to analyze the Fertility trend of Nepal including the latest updated data. To analyze this trend, this article only included the Total Fertility Rate (TFR) and Age Specific Fertility Rate (ASFR). This article also tries to analyze fertility trends of Nepal comparing with Global trend and the trends of other SAARC countries.

\section{Methods and Materials}

This paper follows the quantitative analysis. The entire scope of discussion in this study is based on secondary sources of data. To analyze the trends of Fertility of Nepal, mainly the NDHS-Report 2018 and Population Monograph of Nepal are followed. Besides this, different books, journals, newspapers, national and international reports, Government publications and related websites have been consulted in order to complete the study.

\section{Results and Discussion}

\section{Fertility Trend of Nepal}

Total fertility rate (TFR) in simple term refers to total number of children born or likely to be born to a woman in her life time if she were subject to the prevailing rate of age-specific fertility in the population. TFR of about 2.1 children per woman is called Replacement-level fertility (UN, Population Division, 2015). This value represents the average number of children a woman would have to reproduce herself by bearing a daughter who survives to childbearing age. If replacement level fertility is sustained over a sufficiently long period, each generation will exactly replace itself without any need for the country to balance the population by international migration (WHO, 2018). The total 
fertility rate (TFR) is a more direct measure of the level of fertility than the crude birth rate, since it refers to births per woman. This indicator shows the potential for population change in the country. A rate of two children per woman is considered the replacement rate for a population, resulting in relative stability in terms of total numbers. Rates above two children indicate populations growing in size and whose median age is declining. The age-specific fertility rate measures the annual number of births to women of a specified age or age group per 1,000 women in that age group. An age-specific fertility rate is computed as a ratio. The numerator is the number of live births to women in a particular age group during a period of time, and the denominator an estimate of the number of person-years lived by women in that same age group during the same period of time. It is expressed as births per 1,000 women. The following seven five-year age groups by age of mother at time of birth are presented in the data base: 15 to $19 ; 20$ to $24 ; 25$ to $29 ; 30$ to $34 ; 35$ to $39 ; 40$ to 44 ; and 45 to 49 .

The demographic information shows that Nepal's TFR was above 5.0 until the early 1990s (MOH, 1993). The following table summarizes the fertility trends beyond the 1990s.

Table 1: Age specific and total fertility rates of Nepal

\begin{tabular}{|c|c|c|c|c|c|c|}
\hline \multicolumn{2}{|c|}{ Age Group } & $\begin{array}{c}\text { NFHS } \\
1996\end{array}$ & $\begin{array}{c}\text { NDHS } \\
\mathbf{2 0 0 1}\end{array}$ & NDHS 2006 & NDHS 2011 & $\begin{array}{c}\text { NDHS } \\
\mathbf{2 0 1 6}\end{array}$ \\
\cline { 3 - 7 } & $\mathbf{1 9 9 3 - 1 9 9 5}$ & $\mathbf{1 9 9 8 - 2 0 0 0}$ & $\mathbf{2 0 0 3 - 2 0 0 5}$ & $\mathbf{2 0 0 8 - 2 0 1 0}$ & $\mathbf{2 0 1 4 - 2 0 1 6}$ \\
\hline & $\mathbf{1 5 - 1 9}$ & 0.127 & 0.110 & 0.098 & 0.081 & 0.088 \\
\cline { 2 - 7 } & $\mathbf{2 0 - 2 4}$ & 0.266 & 0.248 & 0.234 & 0.187 & 0.172 \\
\cline { 2 - 7 } A & $\mathbf{2 5 - 2 9}$ & 0.229 & 0.205 & 0.144 & 0.126 & 0.124 \\
\cline { 2 - 7 } F & $\mathbf{3 0 - 3 4}$ & 0.1160 & 0.136 & 0.084 & 0.071 & 0.059 \\
\cline { 2 - 7 } R & $\mathbf{3 5 - 3 9}$ & 0.094 & 0.081 & 0.048 & 0.036 & 0.018 \\
\cline { 2 - 7 } & $\mathbf{4 0 - 4 4}$ & 0.037 & 0.034 & 0.016 & 0.014 & 0.006 \\
\cline { 2 - 7 } & $\mathbf{4 5 - 4 9}$ & 0.015 & 0.007 & 0.002 & 0.005 & 0.002 \\
\hline \multicolumn{2}{|c|}{$\boldsymbol{T F R}$} & $\mathbf{4 . 6 4}$ & $\mathbf{4 . 1 1}$ & $\mathbf{3 . 1 3}$ & $\mathbf{2 . 6 0}$ & $\mathbf{2 . 3}$ \\
\hline
\end{tabular}

Source: Ministry of Health and Population (2017) 
The table 1 shows that both ASFR and TFR have been continuously decreasing since 1990s. The decreasing rate is seen more in between 1998-2005s. Now the TFR is 2.3, so Nepal is in nearer to the replacement level of fertility rate. Although the fertility rate of age group 15-19 has been continuously declining but it would not be so as its expectation. Besides, it seems to increase in between 2008-2016. This age group is considered as early marriage age group. The median age at first marriage among women and men has increased by 1 year over the past decade. On average, women marry 4 years earlier than men (17.9 years versus 21.7 years) (MOH, 2017). Thus, in Nepal the marriage in early age is not still reduced remarkably that's why the fertility rate of this age group is not decreased as comparison to other age groups. The following figure visualizes more clearly about the trends of ASFR.

Figure 1: Trends of ASFR of Nepal in between 1993-2016

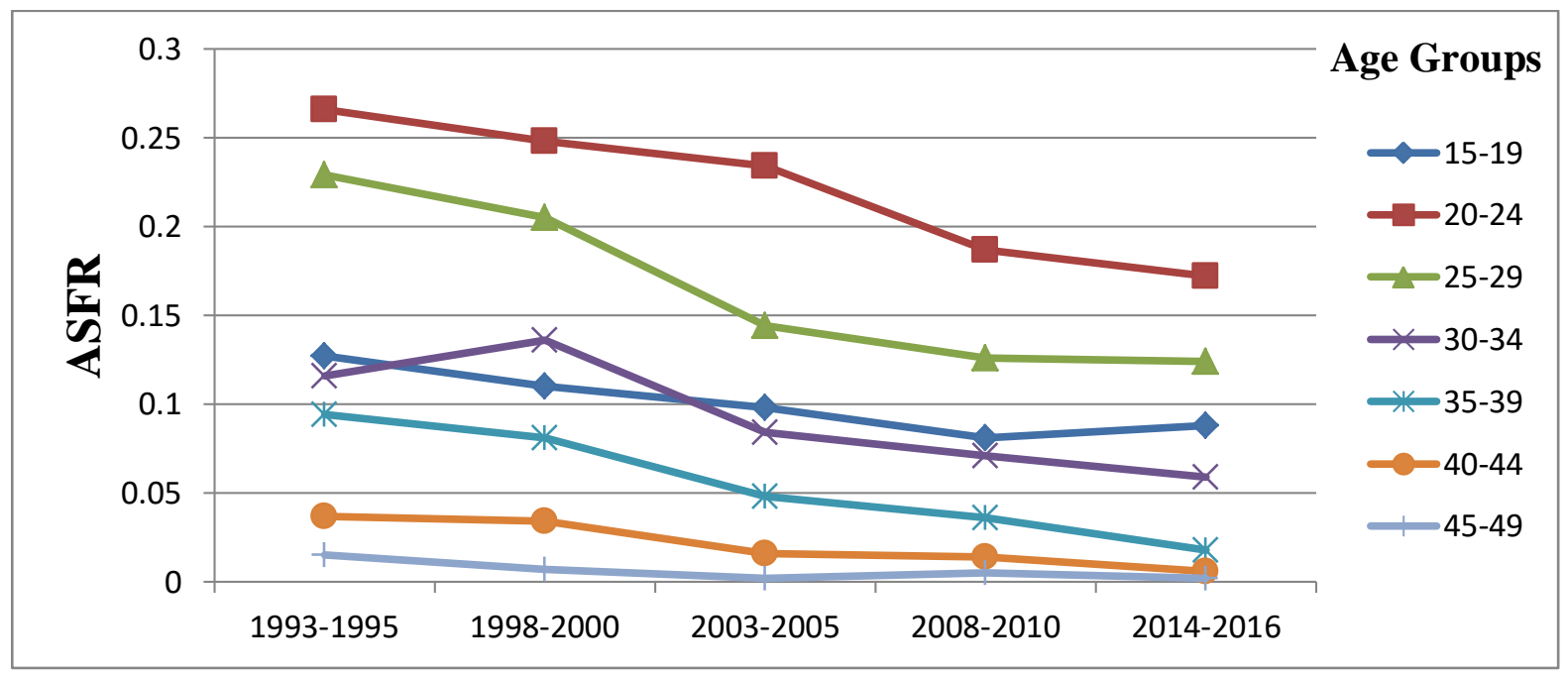

Our society is dominated by the Hindus philosophy, in terms of population carries the deep cultural significance of having sons. Historically, having sizeable families was considered as one of the major characteristics of Nepalese reproductive pattern. This was materialized by universal and early marriage. However, the natural fertility level in Nepal was never as high as compare to our neighbors. According to historical studies, the TFR in the natural fertility regime was around 6-7 in Nepalese society. The NDHS 2011 identify TFR of Nepal is 2.6. This is 1.6 in urban and 2.8 in rural areas. It is still essential to identify 
the risk factors associated with high fertility and to provide services to address those who are at risk. To develop effective strategies for fertility control, it is necessary to identify the factors supporting to higher fertility. The decline in fertility is most pronounced in the five years between 2001 and 2006 (a one-child decline).

\section{Comparative Study of TFR's Trends}

Among our two nearest neighbors, China's total fertility rate has decreased to less than 1.5 births per woman since the late 1990s, and that data from the 2000 and 2010 population censuses as well as sample survey data show that the total fertility rate is at a low level (Guo, 2011, 2015).The 2010 Census of China reported an even lower fertility (TFR 1.19). In India, the Total Fertility Rate (TFR) for the country is 2.3 whereas in rural areas it has been 2.5 and it has been 1.8 in urban areas during 2016 (CBHI, 2018). According to World Population Prospect (2017) the TFR (2010-2015) of other SAARC neighbors also have similar figure, like; Bangaladesh's 2.22, Bhutan's 2.20, Maldives's 2.22, Nepal's 2.23, Pakisthan's 3.72 and Srilanka's 2.11 .

According to the results of the 2015 Revision of World Population Prospects, total fertility is now 2.5 children per woman globally. Nearly half the world lives in belowreplacement level fertility countries. This global average makes wide regional differences. Africa remains the region with the highest fertility at 4.7 children per woman. Europe has the lowest fertility of 1.6 children per woman. Both Asia and Latin America and the Caribbean have total fertility of 2.2 children per woman, closely followed by Oceania with 2.4 children per woman. Middle and Western Africa stand out as having particularly high fertility of over five children per woman. Eastern Asia, Eastern Europe and Southern Europe have very low fertility at fewer than 1.6 children per woman (UN, 2015). The following figure gives the comparative insight of TFR of world and SAARC countries including Nepal. 
Figure 2: Trends of TFR of the world and neighboring SAARC countries

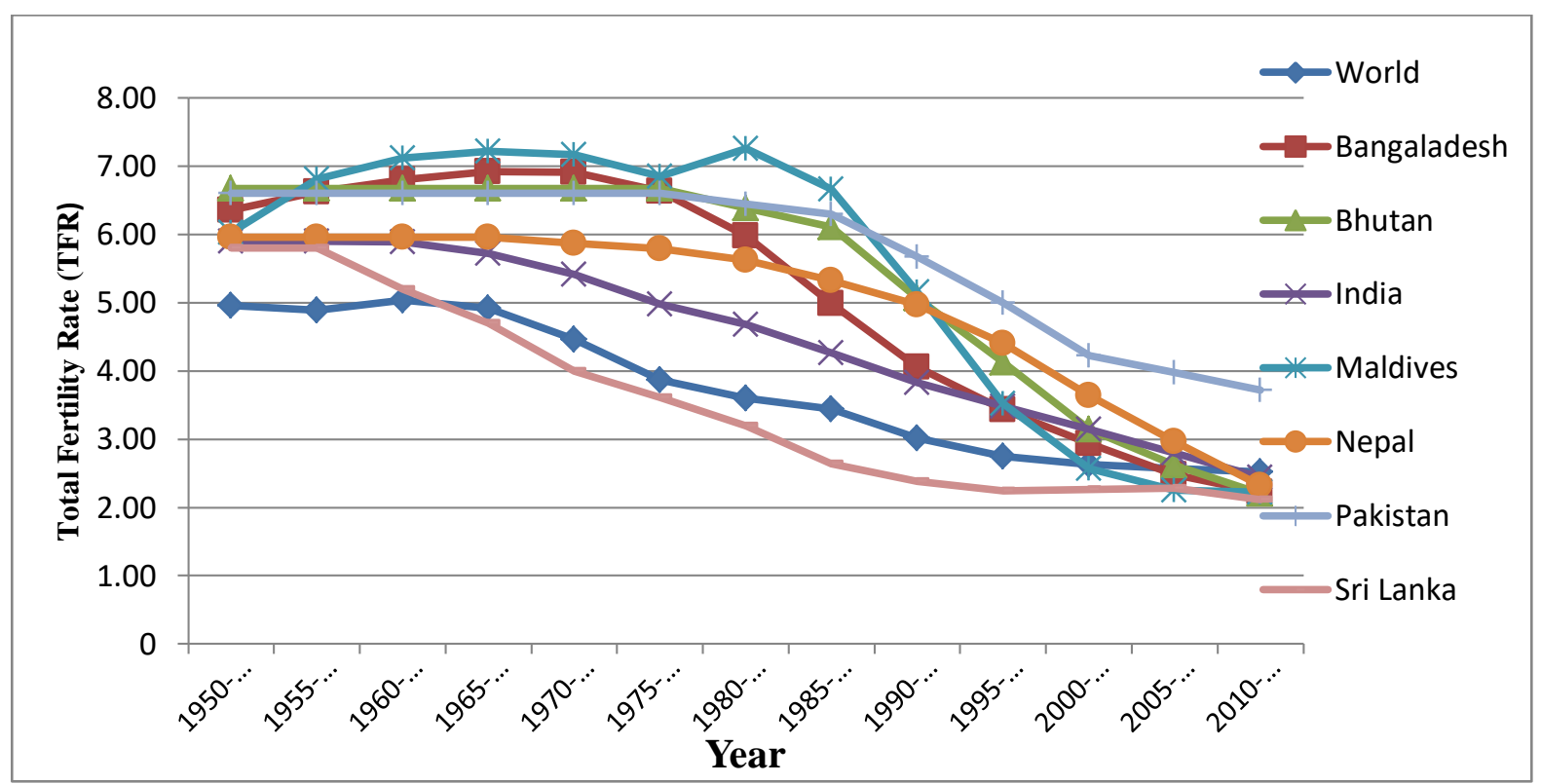

Source: United Nations, Department of Economic and Social Affairs, Population Division (2017)

The figure 2 shows that in the beginning, the TFR of all SAARC countries were more than that of world. But in between past sixty decades, the TFR of this region is remarkably reduced and now it is similar to the world's figure except the Pakistan's. The TFR of Pakistan is still high in comparison to its neighbors.

\section{Conclusion}

As we have see above that the Fertility decline has been occurring for several decades to till now. Not only the fertility but along with, the mortality rate has been also declining due to which the net growth of our population is quite in balance. The awareness about family planning, rise in contraceptive use has been the primary reason for fertility decline. Age at marriage has begun to rise slowly. However, most recently, contraceptive use has not increased to explain the continuous fall in fertility. Other factors such as an increase in male migration and induced abortion have been playing the vital role in the continuous declination of fertility. 
The reduction of fertility has beneficial in many domains, like it opens up completely new employment and educational prospects for young women. It also creates new manpower for job market which helps to boost the economic growth. Many countries, like china have to implement the obligatory plans and policies to control their population boom. But the Nepal, without any such policies can remarkably reduce the fertility rate only by the awareness by means of formal and non formal education. In our societies women do not only give birth to the children, but they have to spend their time to the childcare. Therefore the high fertility tends to lock them up within the domestic domain. In the high fertility societies women's have relatively short lives and in some places still are dominated by the responsibilities of childbirth and childcare. But this is not true place where fertility is low and life expectation at birth is high. But continuous declination of fertility rate below the replacement level is not a good scenario in demography because it causes the negative growth rate of population and increase the dependency ratio. It becomes further disaster in case of the developing country due to the scarcity of economically active population portion.

\section{References}

Adhikari, K., Raya, H. B. (2018). Population Projection of Nepal: A Logistic Approach. Journal of Nepal Mathematical Society (JNMS), Vol. 1, Issue 2: 1-8.

Bhende, A. Asha \& Tara Kanitkar (1992). Principles of Population Studies. Himalaya Publishing House, Mumbai.

CBS (Central Bureau of Statistics) (2014) Population Monograph of Nepal Vol. I (Population Dynamics). Central Bureau of Statistics, Kathmandu.

Central Bureau of Health Intelligence (CBHI), Directorate General of Health Services Ministry of Health \& Family Welfare, Government of India (2018). National Health Profile 2018 (13th Issue). Retrieved from https://cdn.downtoearth.org.in/pdf/NHP2018.pdf

Guo, Z. (2011). Population Census Data Indicates Serious Miscount in Past Population Estimation and Projection. Chinese Journal of Population Science, 6: 2-13.

Guo, Z. (2015). A Clear Understanding of the Risk of Low Fertility In China. International Economic Review,2:100-109. 
80

Kafle R B. (2016). Transition in risks of higher order births in Nepal: a life table analysis. International Journal of Population Studies, vol.2(2): 58-73. http://dx.doi.org/10.18063/IJPS.2016.02.005.

Martine Collumbien, Ian M. Timæus and Laxmi Acharya (1997 ). The Onset of Fertility Decline in Nepal: A Reinterpretation. Retrieved from https://pdfs.semanticscholar.org/ed08/e630f66d4244e0234ac55873401f984bd65a.pdf

Ministry of Health, Nepal; New ERA; and ICF. 2017. Nepal Demographic and Health Survey 2016. Kathmandu, Nepal: Ministry of Health, Nepal.

Ministry of Health.

Ministry of Health., New Era, ORC Macro, et al. (2002). Nepal Demographic and Health Survey 2001. Calverton, Maryland, USA: Family health division, ministry of health Nepal; New Era and ORC Macro.

MOH. (1993).Nepal Fertility, Family Planning and Health Status Survey, 1991. Kathmandu,

PRB. (2011). World Population Data Sheet 2011, WashingtonDC. Population Reference Bureau.

Retherford, Robert \& Thapa,Shyam (2004) Recent trends and components of change in fertility in Nepal. Journal of Biosocial Science 36(6):709-34 .

Shakya \& Gubhaju (2016). Factors Contributing to Fertility Decline in Nepal. Journal of Population and Social Studies, Volume 24 Number 1 January 2016 : 13 - 29.

Sharma, M. P. (2015). The Determinants of Fertility among Women of Reproductive Age in Nepal. The Journal of Development and Administrative Studies (JODAS), Vol. 23(12), pp. 55-68.

United Nations, Department of Economic and Social Affairs, Population Division (2017). World Population Prospects: The 2017 Revision, DVD Edition.

United Nations, Department of Economic and Social Affairs, Population Division (2015). World Fertility Patterns 2015 - Data Booklet (ST/ESA/ SER.

World Health Organization (2018). Health situation and trend assessment. Retrieved From http://www.searo.who.int/entity/health_situation_trends/data/chi/TFR/en/ 